\title{
A Study of Temperature, Microstructure and Hardness Properties of Sn- 3.8Ag-0.7Cu (SAC) Solder Alloy
}

\author{
Amares Singh ${ }^{1, a}$, Ervina Efzan Mhd.Noor ${ }^{2, b}$ \\ ${ }^{1}$ Faculty of Engineering and Built Environment, SEGi University No. 9, Jalan Teknologi, Taman Sains Selangor, Kota Damansara PJU 5, \\ 47810 Petaling Jaya, Selangor, Malaysia \\ ${ }^{2}$ Faculty of Engineering and Technology, Multimedia University, 75450 Ayer Keroh, Melaka, Malaysia
}

\begin{abstract}
Solder alloys are one of the most crucial aspect linking the electrical components to the printed circuit board PCB substrate. Thus, producing a good solder is a must to say in electronic industries. Among major functions of solder alloys are to provide beneficial properties in melting, microstructure and mechanical strand. In this aspect, the $\mathrm{Sn}-3.8 \mathrm{Ag}-0.7 \mathrm{Cu}(\mathrm{SAC})$ solder alloys are recommended as potential candidate to assure these benefits. In this study, the solder possesses melting temperature of, $\mathrm{T}_{\mathrm{M}}=227^{\circ} \mathrm{C}$ which is below the desired soldering temperature, $\mathrm{T}_{\mathrm{M}}=250^{\circ} \mathrm{C}$. Besides, this SAC solder produces well-defined microstructures with Sn-matrix and eutectic phase consisting $\mathrm{Cu}_{6} \mathrm{Sn}_{5}$ and $\mathrm{Ag}_{3} \mathrm{Sn}$ displayed from SEM image, contributes in harvesting good mechanical properties. The SAC solder also provides a high hardness value with an average of $14.4 \mathrm{Hv}$ for Vickers hardness. All these results seem to satisfy the need of a viable solder alloy.
\end{abstract}

\section{Introduction}

Normally, the $\mathrm{Sn}-\mathrm{Pb}$ solder alloys are the most common solder alloys used as medium of interconnection in the electronic packaging industry [1-5]. Its advantages includes low melting temperature of $183^{\circ} \mathrm{C}[6,7]$ and good mechanical properties with high hardness [8-11] making it as an ideal solder alloy. Though, a drawback of this solder is that it is harmful to humans [5,12-14], prompting environmental regulations worldwide to eliminate its usage [15-17]. Some studies have suggested that among the lead-free alloys available, the $\mathrm{Sn}-\mathrm{Zn}[18-$ 20], Sn-Bi [21-23] and $\mathrm{Sn}-\mathrm{Cu}[24,25]$ alloys are quite promising as replacements for lead-based solder. Unfortunately, the $\mathrm{Sn}-\mathrm{Cu}$ holds higher melting temperatures of $237^{\circ} \mathrm{C}$ [26] and the $\mathrm{Sn}-\mathrm{Zn}$ is prone to oxidation [20], while $\mathrm{Sn}-\mathrm{Bi}$ is a low strength solder [21]. Few studies have then identified the $\mathrm{Sn}-\mathrm{Ag}-\mathrm{Cu}$ alloys as the most desirable candidates to replace lead-based solder. Therefore, this paper reports investigation based on the thermal, microstructure and hardness properties of the $\mathrm{Sn}-3.8 \mathrm{Ag}-0.7 \mathrm{Cu}$ (SAC) solder alloy. This paper produces the result to portray the benefits of SAC solder alloy as the alternative solder alloy.

\section{Experimental setup}

The $\mathrm{Sn}-3.8 \mathrm{Ag}-0.7 \mathrm{Cu}$ (SAC) was prepared using tin (99.9\%, Alfa Aesar), argentum (99.9\%, Alfa Aesar) and copper that were melted at $1100{ }^{\circ} \mathrm{C}$ for duration of one hour. This temperature of $1100^{\circ} \mathrm{C}$ for SAC is used due to the high melting temperature of silver $(\mathrm{Ag}) 961^{\circ} \mathrm{C}$ and copper $(\mathrm{Cu}) 1084^{\circ} \mathrm{C}$ and therefore, by having that temperature, it would ensure all elements melt to succesfully produce the SAC solder alloy. The SAC solder alloy was manufactured in a billet form of samples $50 \mathrm{~mm} \times 10 \mathrm{~mm}$ and were ground using $\mathrm{SiC}$ sand paper to remove rough surfaces and then further ground and polished for a better surface finish. These billets were analyzed for microstructure study under magnifications of $(10 \times, 20 \times, 50 \times$, and $100 \times)$ and also using the Scanning Electron Microscopy (SEM) with $1000 \times$ magnifications. Adding to that, the billets samples were taken from these solder alloys for Differential Scanning Calorimetry (DSC) test to evaluate the melting properties with a heat flow temperature from $100^{\circ} \mathrm{C}$ to $300^{\circ} \mathrm{C}$ under nitrogen-based atmosphere. The hardness on the other hand test was conducted based on the Vickers hardness with average of five indentation of $1 \mathrm{kgf}$ load.

\section{Result and discussion}

\subsection{Melting properties}

The DSC curve for SAC (refer Fig. 1) indicates a single sharp endothermic peak which is the melting temperature of $\mathrm{T}_{\mathrm{M}}=218.98^{\circ} \mathrm{C}, 0.9 \%$ higher than the eutectic temperature of a typical SAC due to different atmosphere medium, nitrogen used in this DSC test. Compared to other researchers, the melting temperature of SAC was $<2.6^{\circ} \mathrm{C}[27],<2.22^{\circ} \mathrm{C}[28,29],<2.35^{\circ} \mathrm{C}[11]$ and $<4.62^{\circ} \mathrm{C}$ [30] respectively. This lower melting temperature of SAC

Corresponding author: ${ }^{a}$ amaressinghgill@segi.edu.my: ${ }^{\mathrm{b}}$ ervina.noor@mmu.edu.my 
compared to others is due to the different mass percentage of elements $(3.5 \% \mathrm{Ag}$ and $0.8 \% \mathrm{Cu})$ used in this research which gives a temperature of approximately $218-219^{\circ} \mathrm{C}$ as in the phase diagram. Addition of $\mathrm{Ag}$ in the SAC solder alloy can decrease the temperature of the initial solder. This observation correlates to the study of [17]. The onset temperature of $\mathrm{T}_{\mathrm{S}}=218.2^{\circ} \mathrm{C}$ and an end temperature of $\mathrm{T}_{\mathrm{L}}=221.9^{\circ} \mathrm{C}$ was also plotted in the $\mathrm{DSC}$ curve. Plus, this temperature also falls below the desired soldering temperature of $250^{\circ} \mathrm{C}$. The pasty range meanwhile, is the difference between the melting temperature $\left(T_{M}\right)$ and the solidus temperature $\left(T_{S}\right)$ and is one of the important factors that influence in providing a fine microstructure [27,31]. The pasty range was $\mathrm{T}_{\mathrm{R}}=3.7^{\circ} \mathrm{C}$ for this SAC solder alloy. A short pasty range provides a faster solidification of the solder and it is important in providing better grain refinement and was observed for the SAC solder alloy [32-34]. This result was supported by the research of $[30,35]$. Related to that, rapid solidification provides better and much effective grain fined microstructure of the solder that can enhance the strength directly than the slow cooling rate [12]. It is due to the development of transition structures of fine grain, as in the nanoparticles reinforcement, which in return improves the creep resistance $[12,33]$.

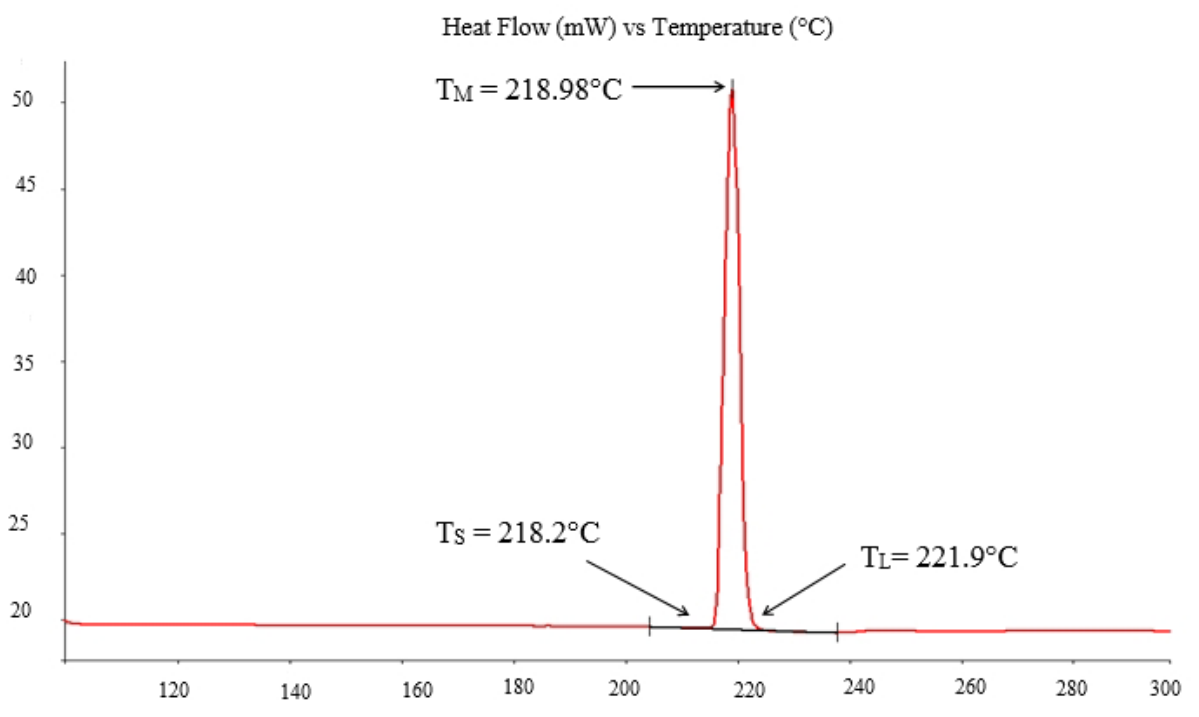

Figure 1. DSC result of SAC solder alloy.

\subsection{Microstructure properties}

The microstructure investigations of SAC solder alloy (refer Fig. 2) shows a dendrite like pattern covered by light and dark phases. The microstructure of this SAC alloy consist of coarse Sn-grains which were identified to be the light phase, while the dark phase is the eutectic regions consisting two phases mainly in the form of intermetallic compounds $\left(\mathrm{Cu}_{6} \mathrm{Sn}_{5}\right.$ and $\left.\mathrm{Ag}_{3} \mathrm{Sn}\right)$, refer Fig. 3 . This observation correlated with the study on $\mathrm{Sn}-\mathrm{Ag}-\mathrm{Cu}$ solder system by $[36,37]$. In this research, this incident was analysed as well and the reason for these different phases and microstructure formations is due to the effect of the solidification process which has also been reported by [38] for the Sn-3.5Ag-0.7Cu. During solidification, a sufficient driving force would be formed and then, the $\mathrm{Sn}$ nucleation would start to occur $[33,39]$. Later, the nucleation will be followed by the growth of the dendrite $\mathrm{Sn}$ in the molten solder where the dendrite structure appeared to be dependent on the content of the Ag and $\mathrm{Cu}[33,39,40]$. The $\mathrm{Sn}$ dendrites will form earlier than the Sn matrix in eutectic phase, while at the Sn matrix, the dendrites grow quickly and forms a large dendrites structure [40,41]. These are reasons for the microstructural appearance of SAC solder alloy in Fig. 2. Further investigation through SEM shows the intermetallic compounds of $\mathrm{Cu}_{6} \mathrm{Sn}_{5}$ was noted as needle like phase and the $\mathrm{Ag}_{3} \mathrm{Sn}$ compound exist as pebble like phases in the SAC as shown Fig. 3 and as forementioned, these intermetallic compounds gives additional strength to the solder alloy. Such confirmation was also justified in the study of [31]. Additional information of elements (based on EDX) in the solder was also shown to assure the existence of the $\mathrm{Sn}, \mathrm{Cu}$ and $\mathrm{Ag}$ element. Noticed from that, the $\mathrm{Sn}$ and $\mathrm{Ag}$ seems to have high percentage correlating the compostion used and also suggest the reactivity of these two elements to produce $\mathrm{Ag}_{3} \mathrm{Sn}$ intermetallic compound [40]. Presence of carbon is due to the carbon tape used during experiment while oxygen could not be avoided, yet oxidation was not immense suggesting the elements of $\mathrm{Sn}, \mathrm{Cu}$ and $\mathrm{Ag}$ reacts among them to produce the intermetallic compunds of $\mathrm{Cu}_{6} \mathrm{Sn}_{5}$ and $\mathrm{Ag}_{3} \mathrm{Sn}$ that contributes to the high strength. 

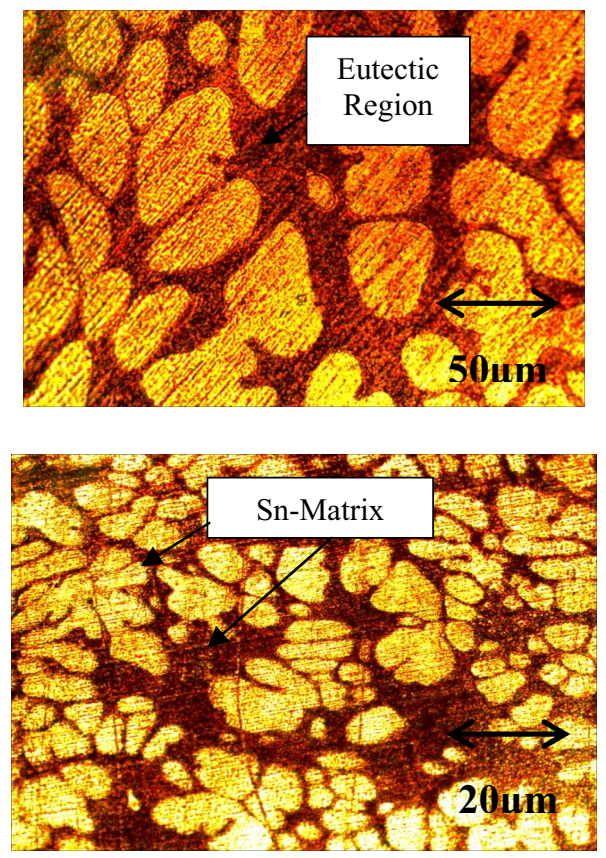

Figure 2. Microstructures of SAC.

An uniform microstructure in solder alloys increases the hardness by resisting deformation and dislocation from taking place easily in the solder [42]. The uniform microstructures were visible as portrayed in Fig. 2. This particular characteristic is very important in giving good strengthening effect in a solder especially in terms of hardness, noted in this study too. The result was in agreement in the study of $[12,26]$. The microstructure of the SAC solder alloy gives an initial reason for the high hardness that was produced. Hence, the high hardness produced here is due to the uniform distribution of the microstructure with Sn-matrix and the eutectic phase (containing $\mathrm{Cu}_{6} \mathrm{Sn}_{5}$ and $\mathrm{Ag}_{3} \mathrm{Sn}$ ) were finely dispersed, giving strengthening effect on the solder alloy.

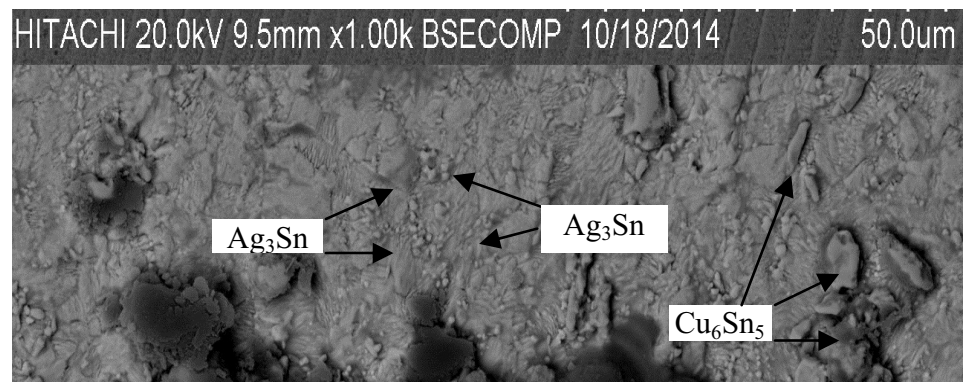

\begin{tabular}{|c|c|}
\hline Elements & Weight (\%) \\
\hline $\mathrm{Sn}$ & 36.24 \\
\hline $\mathrm{Ag}$ & 46.81 \\
\hline $\mathrm{Cu}$ & 0.61 \\
\hline $\mathrm{O}$ & 15.10 \\
\hline $\mathrm{C}$ & 1.24 \\
\hline
\end{tabular}

Figure 3. SEM image of SAC $(1000 \times$ magnification $)$.

\subsection{Hardness}

An average value of $14.4 \mathrm{Hv}$ was attained based on the result ranging from 14.1 to $14.8 \mathrm{Hv}$ for the SAC solder alloy (refer Table 1). This result was similar to the research by [21] with $\mathrm{Sn}-3.5 \mathrm{Ag}-0.7 \mathrm{Cu}$, where the value was only $4 \%$ higher than in this research. The Sn-3.5Ag$0.5 \mathrm{Cu}$ solder alloy was studied in [43] and similarly the percentage difference was only $7 \%$ than SAC suggesting that the $\mathrm{Sn}-\mathrm{Ag}-\mathrm{Cu}$ solder systems have almost equivalent hardness values among them. According to [44], the Sn$\mathrm{Ag}-\mathrm{Cu}$ solder alloy systems are highly resistance to plastic deformation due to its ternary composition. Also, it is clarified from Fig. 2 and 3 which identified a microstructure with compact configuration and wider eutectic phase containing intermetallic compounds will increase the hardness of the solder alloy. As noted by [45], solders with wider eutectic area has higher surface area per unit volume that contributes to increase in strength. A theory called dislocation strengthening mechanism justifies this phenomenon and based on the theory, a wider eutectic area have grain boundaries with smaller surface area making it harder to dislocate the grain boundaries resulting in increased hardness of the solder alloy.

Table 1. Vickers hardness of SAC solder alloy.

\begin{tabular}{cc}
\hline Trials & Vickers Hardness (Hv) \\
\hline 1 & 14.1 \\
2 & 14.3 \\
3 & 14.4 \\
4 & 14.6 \\
5 & 14.8 \\
\hline Average Vickers Hardness & 14.4 \\
(Hv)
\end{tabular}




\section{Conclusions}

The aim of this study is to study the characteristics of the Sn-3.8Ag-0.7Cu (SAC) solder alloy and satisfy the need of a solder to be used in current electronic packaging industry provided with concrete result. Based on this study, the SAC solder alloy has a melting temperature of $218.98^{\circ} \mathrm{C}$, lower than the desired soldering temperature in the electronic industry $\left(250^{\circ} \mathrm{C}\right)$. The SAC solder alloy seems to produces high hardness averaged $14.4 \mathrm{Hv}$ which suggest its reliability in terms of providing resistance to any deformation. This is mainly due to the well defined and wider eutectic phase containing intermetallic compounds of $\mathrm{Cu}_{6} \mathrm{Sn}_{5}$ and $\mathrm{Ag}_{3} \mathrm{Sn}$ that was evident in the microstructure and SEM image. In general, the SAC solder could be an alternative for the lead solder and other lead free solder as it shows better property based on results from this research.

\section{References}

1. M. Abtew, G. Selvaduray, Materials Science and Engineering 27, 19-141 (2000)

2. G. Humpston, D. M. Jacobson, Materials Park Ohio, 1-47 (2004)

3. C.L. Ning, Newnes, an imprint of ButterworthHeinemann, (2002)

4. D.C. Whalley, Journal of Materials Processing Technology 150, 134-144 (2004)

5. J. Shen, Y.C. Chan, Microelectronics Reliability 49, 223-234 (2009)

6. G. Lili, B.X. Song, Z. Liang, S. Zhong, J. Feng, D. Wei, Y. Sheng-lin, Z. Guang, Microelectronic Engineering 87, 2025-2034 (2010)

7. A. Kar, G. Mainak, N.G. Rabindra, S.M. Bhaskar, K.R Ajoy, Materials Letters 62, 151-154 (2008)

8. T.C. Hong, W. Chunqing, L. Mingyu, T. Dewen, J. Mater. HSci. Technol. 23, (2007)

9. T. Laurila, V. Vuorinen, SciTopics, Retrieved April 16,2012

10. A.S.M.A. Haseeb, M.M. Arafat, R.J. Mohd, Materials Characterization 64, 27-35 (2012)

11. T. Fouzder, S. Ismathullakhan, Y.C. Chan, A. Sharif, K.C.Y. Winco, Journal of Alloys and Compounds 509, 1885-1892 (2011)

12. R. Patrick, N. Grace, H.R. Greg, H. Robert, P. Swaminath, C. Flynn, G. Alexander, APEX (2001)

13. A.A. El-Daly, Y. Swilem, M.H. Makled, M.G. ElShaarawy, A.M. Abdraboh, Journal of Alloys and Compounds 484, 134-142 (2009)

14. Z. Jian, S. Yangshan, X. Feng, Journal of Alloys and Compounds 397, 260-264 (2005)

15. E.M.N. Ervina, M.S. Nurulakmal, K.Y. Cheong, A. Tadashi, B.I. Ahmad, H. Zuhailawati, Journal of Alloys and Compounds 507, 290-296 (2010)

16. L.Q. Zhao, W. Xiu-min, W. Lai, Journal of Alloys and Compounds 375, 196-201 (2004)

17. A.A. El-Daly, A.E Hammad, Journal of Alloys and Compounds 509, 8554-8560 (2011)
18. L.L. Duan, D.Q. Yu, S.Q. Han, H.T. Ma, L. Wang, Journal of Alloys and Compounds 381, 202-207 (2004)

19. E.M.N. Ervina, A. Singh, $35^{\text {th }}$ International Electronics Manufacturing Technology, 59 (2012)

20. R. Mayappan, Z.A. Ahmad, Intermetallics 18, 730735 (2010)

21. T.Y. Kang, Y.Y. Xiu, J.J. Wang, W.P. Tong, C.Z. Liu, J. Mater. Sci. Technol. 27, 741-745 (2011)

22. L. Shen, S. Pradita, C. Zhong, Materials Science \& Engineering A 558, 253-258 (2012)

23. J. Chriastelova, M. Ozvold, Journal of Alloys and Compounds 457, 323-328 (2008)

24. A. Mansur, F. Tama, A. Sharif, K.G. Asit, Y.C. Chan, Microelectronics Reliability 50, 1134-1141 (2010)

25. W.M. Chen, S.K Kang, C.R Kao, Journal of Alloys and Compounds 520, 244-249 (2012)

26. M.R. Harrison, J.H. Vincent, H.A.H Steen, Soldering and Surface Mount Technology 13, 21-38 (2001)

27. C.L. Chuang, L.C. Tsao, H.K Lin, L.P Feng, Materials Science \& Engineering A 558, 478-484 (2012)

28. S.Y. Chang, C.C. Jain, T.H. Chuang, L.P. Feng, L.C. Tsao, Materials and Design 32, 4720-4727 (2011)

29. L.C.Tsao, S.Y. Chang, C.I. Lee, W.H. Sun, C.H. Huang, Materials and Design 31, 4831-4835 (2010)

30. L.C. Tsao, S.Y. Chang, Materials and Design 31, 990-993 (2010)

31. H.R. Kotadia, O. Mokhtaria, M.P. Clode, M.A Green, S.H Mannan, Journal of Alloys and Compounds 511, 176-188 (2012)

32. M. Zequn, A.H. Helen, A.V.P Hubert, LowTemperature Solders Hewlett-Packard, (1996)

33. R.M. Shalaby, Journal of Alloys and Compounds 505, 113-117 (2010)

34. P. Lobry, L. Blaz, M. Sugamata, A. Kula, International Scientific Journal 49, (2011)

35. L. Zhang, W.H. Cheng, H.G. Yong, G.H. Ji, W.Z. Yong, Y.W Xu, Microelectronics Reliability 52, 559-578 (2012)

36. F.X. Che, W.H. Zhu, S.W.P. Edith, Zhang X.W., Zhang X.R, Journal of Alloys and Compounds 507, 215-224 (2010)

37. D.Q. Yu, J. Zhao, L. Wang, Journal of Alloys and Compounds 376, 170-175 (2004)

38. W.Y Jeong, I.N. Bo, K.K. Bong, C.S. Chang, B.J Seung, Journal of Alloys and Compounds 486, 142147 (2009)

39. J. Keller, D. Baither, U. Wilke, G. Schmitz, Acta Materialia 59, 2731-2741 (2011)

40. J. Gong, L. Changqing, P.C. Paul, V.S Vadim, Scripta Materialia 60, 333-335 (2009)

41. S. Wiese, K.J Wolter, Microelectronics Reliability 44, 1923-1931 (2004)

42. L.C. Tsao, C.H. Huang, C.H Chung, R.S Chen, Materials Science and Engineering A 545, 194- 200 (2012)

43. E.D. George, Copyright Mechanical Metallurgy, Mcgraw-Hill Book Company UK Limited, (1988) 
44. E.M.N. Ervina, S. Amares, T.C Yap, Soldering \& Surface Mount Technology 25, (2013)
45. H.J. Lin, T.H Chuang, Journal of Alloys and Compounds 500, 167-174 (2010) 